\title{
Results of a whole genome scan targeting QTL for growth and carcass traits in a Piétrain $\times$ Large White intercross
}

\author{
Carine Nezer, Laurence Moreau, \\ Danny Wagenaar, Michel Georges* \\ Department of Genetics, Faculty of Veterinary Medicine, \\ University of Liège (B43), 20 Bd de Colonster, 4000 Liège, Belgium
}

(Received 13 November 2001; accepted 29 January 2002)

\begin{abstract}
We herein report the results of a whole genome scan performed in a Piétrain $\times$ Large White intercross counting 525 offspring to map QTL influencing economically important growth and carcass traits. We report experiment-wide significant lod scores $(>4.6)$ for meatiness and fat deposition on chromosome SSC2, and for average daily gain and carcass length on chromosome SSC7. Additional suggestive lod scores (>3.3) for fat deposition are reported on chromosomes SSC1, SSC7 and SSC13. A significant dominance deviation was found for the QTL on SSC1, while the hypothesis of an additive QTL could not be rejected for the QTL on SSC7 and SSC13. No evidence for imprinted QTL could be found for QTL other than the one previously reported on SSC2.
\end{abstract}

\section{QTL mapping / pig / growth traits / carcass traits}

\section{INTRODUCTION}

The availability of genome-wide microsatellite maps for an increasing number of species has spurred efforts to dissect the molecular basis of the genetic variation for a broad range of medically, agriculturally or fundamentally important heritable quantitative traits (e.g. $[1,6])$. Interest in QTL mapping experiments has been considerable in livestock production science because of the opportunities to exploit mapping data in more effective marker assisted selection (MAS) schemes. Implementation of QTL mapping experiments in livestock species has been facilitated by (i) the availability of large data sets of phenotypic records collected as part of most breeding programs, (ii) the extensive groundwork invested in the estimation of variance components including estimates of heritability, and (iii) the possibility to design matings at will.

\footnotetext{
* Correspondence and reprints

E-mail: michel.georges@ulg.ac.be
} 
In animal genetics, QTL mapping experiments are either performed in outbred populations, targeting the loci that contribute to the within population variance, or in experimental crosses aiming at the genetic basis of the between population variance. While the former approach has been extensively used in cattle, leading to the identification of several QTL affecting for instance milk production, the latter has been the preferred design in species such as pigs and poultry (e.g. [1]).

In this work, we report results of a QTL mapping experiment targeting a series of growth and carcass characteristics of economic importance in pig breeding, performed in a Piétrain $\times$ Large White intercross. The Piétrain breed, originating from the village of Piétrain in Belgium, is characterized by its exceptional muscularity and leanness. Piétrain boars are therefore used for their carcass improving ability in terminal crosses all over the world. However, Piétrain animals have relatively poor growth features (such as daily gain), and modest mothering characteristics and milk production. Moreover, a large proportion of the animals suffer from malignant hyperthermia and the associated porcine stress (PSS) and pale soft exsudative (PSE) syndromes. In many respects, the Large White, also known as Yorkshire, have complementary features. They produce lower grade, fattier carcasses, but grow faster, are prolific and good rearers and are resistant to stress. Crosses between these two breeds therefore offer the possibility to identify the allelic variants responsible for these differences. This opportunity is particularly relevant since the corresponding variation is being exploited in the present breeding programs.

It is well established that a $\mathrm{C} \rightarrow \mathrm{T}$ transition in the $C R C$ gene is responsible for malignant hyperthermia and associated PSS/PSE syndromes affecting the majority of Piétrain individuals. The same mutation or closely linked DNA sequence variants have also been shown to have a pleiotropic effect on several carcass and growth traits $(e . g$. $[7,17])$. Depending on the trait considered, the $\mathrm{C} \rightarrow \mathrm{T} C R C$ mutation has been shown to account for $0 \%$ to nearly $100 \%$ of the phenotypic differences observed between the two breeds [9]. For the $\mathrm{pH}$ measured after slaughter, a measure of meat quality, the $C R C$ genotype virtually explains all the difference between the Piétrain and Large White. For all other traits, however, the $C R C$ genotype accounts for only part of this difference, implying the existence of other contributing genes. The aim of the present experiment was to map some of these QTL.

\section{MATERIALS AND METHODS}

\subsection{Pedigree material}

The pedigree material used to map QTL was selected from a previously described Piétrain $\times$ Large White F2 pedigree comprising $>1800$ individuals [9]. To assemble this F2 material, 27 Piétrain boars were mated to 20 Large 
White sows to generate an F1 generation comprising 456 individuals. $31 \mathrm{~F} 1$ boars were mated to 82 unrelated F1 sows from 1984 to 1989, yielding a total of 1862 F2 offspring. F1 boars were mated on average to 7 females, and F1 sows to an average of 2.7 males. Average offspring per boar were 60 and per sow 23.

Biological material was stored for none of the individuals of the parental generation, 31\% (142 individuals) from the F1 generation, and 60\% (1 125 individuals) of the F2 generation. Based on sample availability and family structure, we selected a set of $528 \mathrm{~F} 2$ individuals to perform a whole genome scan in search for QTL affecting growth and carcass characteristics. These F2 individuals are the offspring of $20 \mathrm{~F} 1$ boars mated on average to four females, and $45 \mathrm{~F} 1$ sows mated to an average of 1.8 males. Average offspring per boar were 26.4 and per sow 11.7. Selection was not based on performance criteria.

\subsection{Phenotypic information}

\subsubsection{Data collection}

A total of 15 distinct phenotypes recorded in the F2 generation were selected for QTL mapping. These included one growth trait and 14 carcass traits (Tab. I). A detailed description of the respective traits can be found in Hanset et al. [9]. Table I reports for each trait the number of F2 individuals with usable measurements, as well as the corresponding mean and standard deviation measured in the F2 generation.

\subsubsection{Data processing}

Individual phenotypes were pre-adjusted for fixed effects and covariates that proved to significantly affect the corresponding trait. Variables included in the model were selected by stepwise regression, except for the $C R C$ genotype which was considered for all traits. Table I summarizes which fixed effects and covariates were used to correct the respective traits, and reports the \% of the variance accounted for by the full model as well as by the genotype at the $C R C$ locus.

\subsection{Marker genotyping}

One hundred and thirty seven microsatellite markers spread across the porcine genome were selected from published marker maps [19]. Marker genotyping was performed as previously described [8]. Genotype interpretation was performed independently by two experienced scientists, and their interpretation was confronted after double entry in a purpose-build Access database. The genotype at the $C R C$ locus was determined using conventional methods as described [7]. 


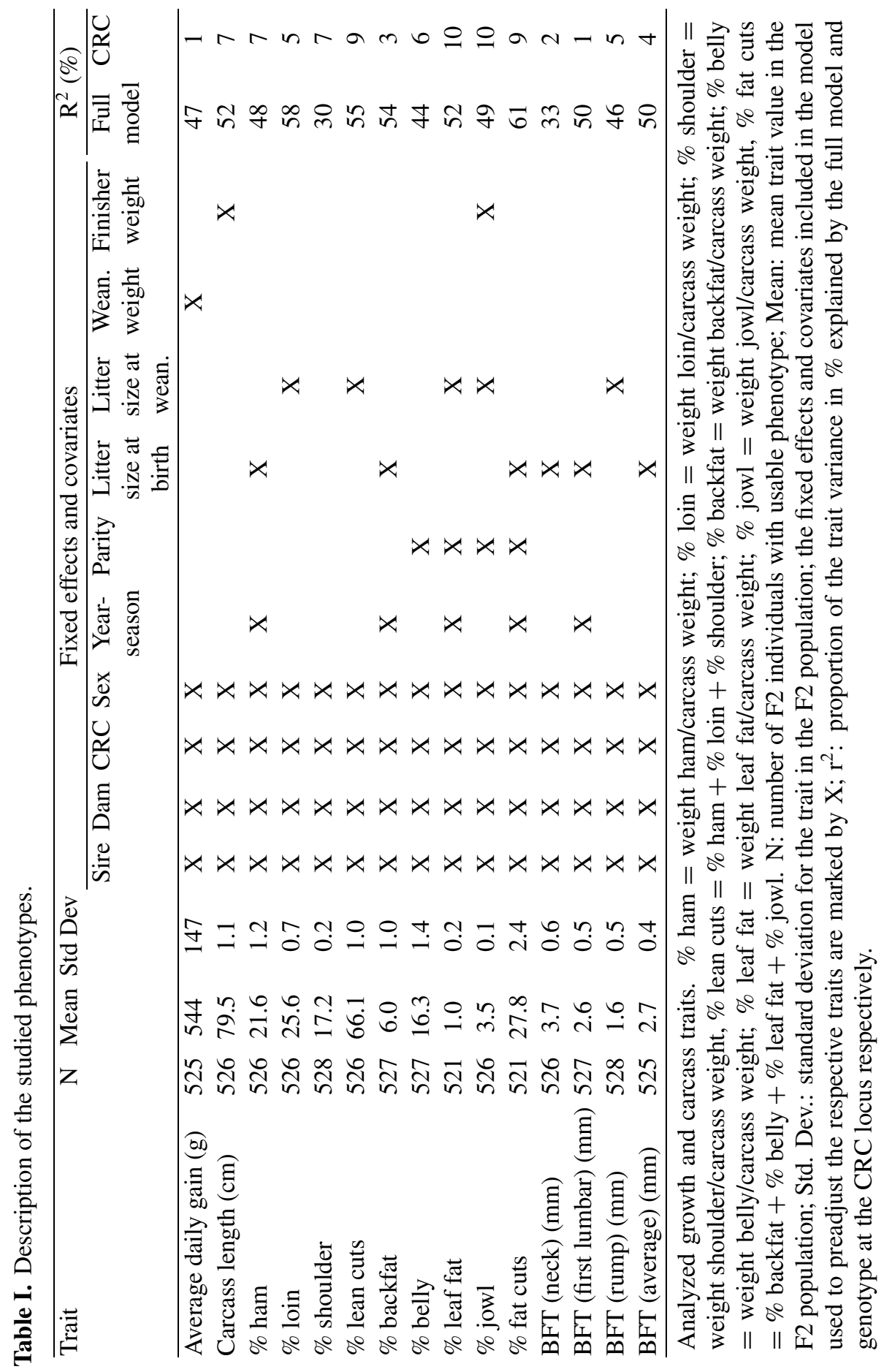




\subsection{Map construction}

Marker maps were constructed using the TWOPOINT, BUILD and CHROMPIC options of the CRIMAP package [15]. In these analyses, full-sib families related via the boar or sow were disconnected and treated independently.

The statistical significance of the difference between male and female recombination rates was estimated from:

$$
-2 \ln \frac{L\left(\text { data } \mid \theta_{\mathrm{m}} \neq \theta_{\mathrm{f}}\right)}{L\left(\text { data } \mid \theta_{\mathrm{m}}=\theta_{\mathrm{f}}\right)}=\chi_{1}^{2}
$$

where $L\left(\right.$ data $\left.\mid \theta_{\mathrm{m}} \neq \theta_{\mathrm{f}}\right)$ corresponds to the likelihood of the data under a model with male and female sex-specific recombination rates, while $L\left(\right.$ data $\left.\mid \theta_{\mathrm{m}}=\theta_{\mathrm{f}}\right)$ corresponds to the likelihood of the data assuming a unique recombination rate identical in both sexes.

\subsection{Mapping Mendelian QTL}

Conventional QTL mapping was performed using a multipoint maximum likelihood method. The applied model assumed one segregating QTL per chromosome, and fixation of alternate QTL alleles in the respective parental lines: Piétrain $(P)$ and Large White $(L W)$. A specific analysis program had to be developed to account for the missing genotypes of the parental generation, resulting in the fact that the parental origin of the F1 chromosomes could not be determined. Using a typical "interval mapping" strategy, a hypothetical QTL was moved along the marker map using user-defined steps. At each position, the likelihood $(L)$ of the pedigree data was computed as:

$$
L=\sum_{\varphi=1}^{2^{r}} \prod_{i=1}^{n} \sum_{G=1}^{4}\left[P\left(G \mid M_{i}, \theta, \varphi\right) P\left(y_{i} \mid G\right)\right]
$$

where

$\sum_{\varphi=1}^{2^{r}}: \quad$ is the sum over all possible marker-QTL phase combinations of the F1 generation. Since there are two possible phases for each parent (left chromosome $P$ or right chromosome $P$ ), there are a total of $2^{r}$ combinations for $r \mathrm{~F} 1$ parents.

$\prod_{i=1}^{n}: \quad$ is the product over the $n \mathrm{~F} 2$ individuals. 
$\sum_{G=1}^{4}: \quad$ is the sum, for the $i$-th F2 offspring, over the four possible QTL genotypes: $P / P, P / L W, L W / P$ and $L W / L W$.

$P\left(G \mid M_{i}, \theta, \varphi\right)$ : is the probability of the considered QTL genotype, given (i) $M_{i}$ : the marker genotype of the $i$-th F2 offspring and its F1 parents, (ii) $\boldsymbol{\theta}$ : the vector of recombination rates between adjacent markers and between the hypothetical QTL and its flanking markers, and (iii) $\varphi$ : the considered marker-QTL phase combination of the F1 parents. The recombination rates and the marker linkage phase of the F1 parents were assumed to be known when computing this probability. Both were determined using CRIMAP in the map construction phase (see above). Sex-averaged recombination rates were used for QTL mapping.

$P\left(y_{i} \mid G\right)$ : is the probability density of the corrected phenotypic value $\left(y_{i}\right)$ of offspring $i$, given the QTL genotype under consideration. This probability density is computed from the normal density function:

$$
P\left(y_{i} \mid G\right)=\frac{1}{\sqrt{2 \pi} \sigma} \mathrm{e}^{\frac{-\left(y_{i}-\mu_{\mathrm{G}}\right)^{2}}{2 \sigma^{2}}}
$$

where $\mu_{\mathrm{G}}$ is the phenotypic mean of the considered QTL genotype (PP, $\mathrm{PL}, \mathrm{LP}$ or LL) and $\sigma^{2}$ the residual variance. $\sigma^{2}$ was considered to be the same for the four QTL genotypic classes.

The values of $\mu_{\mathrm{PP}}, \mu_{\mathrm{PL}}=\mu_{\mathrm{LP}}, \mu_{\mathrm{LL}}$ and $\sigma^{2}$ maximizing $L$ were determined using the GEMINI optimisation routine [14].

The likelihood obtained under this alternative $\mathrm{H}_{1}$ hypothesis was compared with the likelihood obtained under the null hypothesis $\mathrm{H}_{0}$ of no QTL, in which the phenotypic means of the four QTL genotypic classes were forced to be identical. The difference between the logarithms of the corresponding likelihoods yields a lod score measuring the evidence in favour of a QTL at the corresponding map position.

Note that as the marker-QTL linkage phase of the F1 individuals is unknown, the likelihood surface under $\mathrm{H}_{1}$ is characterized by two equiprobable maxima corresponding to permutations of the estimates of $\mu_{\mathrm{PP}}$ and $\mu_{\mathrm{LL}}$. As a consequence, we report the absolute values of $\left[\mu_{\mathrm{PP}}-\mu_{\mathrm{LL}}\right]$ and $\left[\mu_{\mathrm{PL} / \mathrm{LP}}-\left(\mu_{\mathrm{PP}}+\mu_{\mathrm{LL}}\right) / 2\right]$ corresponding respectively to estimates of $|2 a|$ and $|d|$ as defined in Falconer and Mackay [5].

\subsection{Lod score thresholds for significant QTL}

The lod score threshold, $T$, associated with a one-trait, genome-wide significance level $\left(\alpha_{1 \mathrm{G}}\right)$ of 0.05 , was computed such that:

$$
\alpha_{1 \mathrm{G}}=1-\mathrm{e}^{\mu_{T}}=0.05
$$


where $\mu_{T}$ corresponds to the expected number of chromosome regions for which the lod score (z) exceeds the threshold value $T$ by chance alone. Following the recommendation of Kruglyak and Lander [12] for a map with intermediate map density, $\mu_{T}$ was computed as:

$$
\mu_{T}=\left(C+\frac{\rho G}{\Delta}\right) P(z>T)
$$

where $C$ corresponds to the number of chromosomes $(=19), \rho$ to the rate of crossovers per Morgan ( $=1.5$ for an F2 population in which both additive and dominance components are estimated), $G$ to the length of the genome measured in Morgans ( $=21$ - see hereafter), $\Delta$ to the average distance between adjacent markers in Morgans $(=0.18-$ see hereafter $)$, and $P(z>T)$ to the nominal probability that the lod score $z$ exceeds the threshold value $T . P(z>T)$ was calculated knowing that:

$$
z=\log _{10} L R=\frac{\ln L R}{\ln 10} \sim \frac{\chi_{2}^{2}}{2 \ln 10}
$$

in which $L R$ corresponds to the ratio between the likelihood of the data under the alternative hypothesis $\mathrm{H}_{1}$ assuming a QTL at the considered map position and the likelihood of the data under the null hypothesis $\mathrm{H}_{0}$ of no QTL, and $\chi_{2}^{2}$ corresponds to a random variable having a chi-squared distribution with two degrees of freedom since both an additive and dominance component are estimated under $\mathrm{H}_{1}$. This approach yields a one-trait, genome-wide lod score threshold associated with a Type I error of $5 \%\left(\alpha_{1 \mathrm{G}}=0.05\right)$ of 3.58 .

This one-trait, genome-wide threshold was adjusted to account for the fact that we analyzed not one but 15 distinct traits. Using the procedure described by Spelman et al. [22] we determined that - because of their correlations the 15 analyzed traits were in fact equivalent to the analysis of 11 independent traits. A Bonferroni correction corresponding to 11 independent tests was therefore applied to the one-trait, genome-wide threshold. This yielded a lod score value of 4.6 to obtain a multiple-trait, genome-wide significance level $\left(\alpha_{\mathrm{MG}}\right)$ of 0.05 , corresponding to a single-trait, genome-wide significance level $\left(\alpha_{1 \mathrm{G}}\right)$ of 0.0047 .

\subsection{Lod score thresholds for suggestive QTL}

Following Kruglyak and Lander [13], the lod score threshold, T, "suggesting" linkage in a one-trait, genome-wide analysis was computed from equation (5) assuming a value of $1 / 11$ for $\mu_{T}$, i.e. the expected occurrence of one chromosome region on average for which the lod score $(\mathrm{z})$ exceeds the threshold value $T$ by chance alone, when analyzing 11 independent traits. This yields a lod score threshold of 3.3. 


\subsection{Testing for dominance}

When a significant or suggestive QTL was found, we tested the significance of the dominance deviation, $d$, by comparing the maximum likelihood of the pedigree data under $\mathrm{H}_{1}$ (defined as above and allowing for dominance), with the likelihood of the data assuming the existence of an additively acting QTL at the same map position (referred to as the $\mathrm{H}_{\mathrm{A}}$ hypothesis). $\mathrm{H}_{\mathrm{A}}$ was computed according to equation (2), however assuming that $d=0$, therefore that $\mu_{\mathrm{PL}}=\mu_{\mathrm{LP}}=\left(\mu_{\mathrm{PP}}+\mu_{\mathrm{LL}}\right) / 2$. The significance of the dominance deviation, $d$, was tested knowing that:

$$
-2 \ln \frac{L\left(\text { data } \mid \mathrm{H}_{1}\right)}{L\left(\text { data } \mid \mathrm{H}_{\mathrm{A}}\right)} \sim \chi_{1}^{2}
$$

\subsection{Testing for imprinted QTL}

To test for imprinted QTL, we assumed that only the QTL alleles transmitted by the parent of a given sex would have an effect on phenotype, the QTL alleles transmitted by the other parent being "neutral". The likelihood of the pedigree data under these hypotheses were also computed using equation (2). To compute $P\left(y_{i} \mid G\right)$, however, the phenotypic means of the four QTL genotypes were set at $\mu_{\mathrm{PP}}=\mu_{\mathrm{PL}}=\mu_{\mathrm{P}}$ and $\mu_{\mathrm{LP}}=\mu_{\mathrm{LL}}=\mu_{\mathrm{L}}$ to test for a QTL for which the paternal allele only is expressed ( $\mathrm{H}_{\mathrm{IP}}$ hypothesis), and $\mu_{\mathrm{PP}}=\mu_{\mathrm{LP}}=\mu_{\mathrm{P}}$ and $\mu_{\mathrm{PL}}=\mu_{\mathrm{LL}}=\mu_{\mathrm{L}}$ to test for a QTL for which the maternal allele only is expressed ( $\mathrm{H}_{\mathrm{IM}}$ hypothesis). It is assumed in this notation that the first subscript refers to the paternal allele, the second subscript to the maternal allele.

Two distinct approaches were followed to measure the statistical significance of the $\mathrm{H}_{\mathrm{IM}}$ and $\mathrm{H}_{\mathrm{IP}}$ hypotheses. First, for significant and suggestive QTL identified using a Mendelian model $\left(\mathrm{H}_{1}\right)$, we compared the likelihood of the data under $\mathrm{H}_{I M}$ and $\mathrm{H}_{I P}$ with that under $\mathrm{H}_{1}$ (at the most likely position under $\mathrm{H}_{1}$ ). $\mathrm{H}_{1}$ would be rejected in favor of $\mathrm{H}_{\mathrm{IM}}$ or $\mathrm{H}_{\mathrm{IP}}$ if for either of these $-2 \ln (L R)$ would yield a significant chi-squared value. This is in essence the approach that was followed by Nezer et al. [18] to identify the imprinted QTL on chromosome 2.

In addition, we performed a whole genome scan under the $\mathrm{H}_{\mathrm{IM}}$ and $\mathrm{H}_{\mathrm{IP}}$ hypotheses, in the hope of uncovering imprinted QTL that would have gone unnoticed under the $\mathrm{H}_{1}$ hypothesis. Lod scores were computed as:

$$
z=\log _{10} \frac{L\left(\text { data } \mid \mathrm{H}_{\mathrm{IM} / \mathrm{IP}}\right)}{L\left(\text { data } \mid \mathrm{H}_{0}\right)} .
$$

Significant and suggestive lod score thresholds were determined using equations (4, 5 and 6) as described above, however, assuming a value of 1 for $\rho$, a chi-squared distribution with one degree of freedom for $z \times 2 \ln (10)$, and a Bonferroni correction corresponding to 11 (number of traits) $\times 2\left(\mathrm{H}_{\mathrm{IM}}\right.$ and $\left.\mathrm{H}_{\mathrm{IP}}\right)=$ 
22 independent tests. This yielded a lod score threshold of 4 for significant linkage and 2.8 for suggestive linkage. If new QTL were to be found using this approach, we would still confront the likelihood of the data under $\mathrm{H}_{\mathrm{IM}}$ or $\mathrm{H}_{\mathrm{IP}}$ with that under the more conservative $\mathrm{H}_{1}$ hypothesis before accepting the hypothesis of an imprinted QTL.

\subsection{Information content mapping}

In an F2 design, the information content along the used marker map can be measured according to Knott et al. [11] as:

$$
\frac{\sum_{i=1}^{n}\left[\left(P_{Q Q}-P_{q q}\right)^{2}+2\left(P_{Q q}-0.5\right)^{2}\right]}{n-1}
$$

where $P_{Q Q}, P_{q q}$ and $P_{Q q}$ are the probabilities that the $i$-th offspring has respectively the $Q Q, Q q$ or $q q$ genotype at the considered map position given flanking marker data. In these, $Q$ and $q$ are the QTL alleles assumed to be fixed in the respective parental lines.

In the present study, $P_{Q Q}, P_{q q}$ and $P_{Q q}$ could not be computed as such, because the parental generations were not genotyped. However, for each F2 offspring, we could compute four probabilities referred to as $P_{\mathrm{LS}}, P_{\mathrm{RS}}$ (= $\left.1-P_{\mathrm{LS}}\right), P_{\mathrm{LD}}$ and $P_{\mathrm{RD}}\left(=1-P_{\mathrm{LD}}\right)$, corresponding to the probabilities that it received respectively the "left" $\left(P_{\mathrm{LS}}\right)$ or "right" $\left(P_{\mathrm{RS}}\right)$ homologue from its sire, and the "left" $\left(P_{\mathrm{LD}}\right)$ or "right" $\left(P_{\mathrm{RD}}\right)$ homologue from its dam, at a given map position. From these probabilities, the information content at map position $\mathrm{p}\left(I C_{\mathrm{p}}\right)$ was measured as:

$$
I C_{\mathrm{p}}=\frac{\sum_{i=1}^{n}\left[\left(P_{\mathrm{LS}}-P_{\mathrm{RS}}\right)^{2}+\left(P_{\mathrm{LD}}-P_{\mathrm{RD}}\right)^{2}\right]}{2 n-1} .
$$

In this $\left(P_{\mathrm{LS}}-P_{\mathrm{RS}}\right)^{2}$ and $\left(P_{\mathrm{LD}}-P_{\mathrm{RD}}\right)^{2}$ measure the ability to discriminate which homologue ("left" or "right") was transmitted by respectively the sire and the dam to offspring $i$. Values for $\left(P_{\mathrm{LS}}-P_{\mathrm{RS}}\right)^{2}$ and $\left(P_{\mathrm{LD}}-P_{\mathrm{RD}}\right)^{2}$ range from 0 (no information) to 1 (perfect information). $I C_{\mathrm{p}}$ measures the average information content across the $2 n$ chromosomes of the $\mathrm{F} 2$ generation.

\section{RESULTS}

\subsection{Map construction and information content}

One hundred and thirty two out of the 137 genotyped markers could be ordered with odds versus all alternative orders superior to 1000:1. The 
Table II. Main features of the generated microsatellite marker map.

\begin{tabular}{|c|c|c|c|c|c|c|c|c|c|c|c|c|c|}
\hline Chrom. & SA-cM & M-cM & F-cM & $\mathrm{p}$-value & $\mathrm{N}^{\circ}$ & I1 & I2 & I3 I & I4 I & I5 & I6 & I7 & I8 \\
\hline 1 & 117 & 142 & 109 & **** & 7 & 27 & 12 & 226 & $\begin{array}{ll}6 & 2\end{array}$ & 25 & 23 & & \\
\hline 2 & 135 & 122 & 152 & $* * * *$ & 9 & 1 & 6 & 172 & 292 & 21 & 8 & 4 & 48 \\
\hline 3 & 145 & 133 & 157 & $* * * *$ & 8 & 48 & 21 & 88 & 82 & 21 & 17 & 22 & \\
\hline 4 & 129 & 116 & 148 & $* * * *$ & 8 & 25 & 17 & $17 \quad 1$ & 142 & 26 & 19 & 11 & \\
\hline 5 & 121 & 101 & 142 & $* * * *$ & 6 & 62 & 15 & $\begin{array}{ll}8 & 1\end{array}$ & 102 & 25 & & & \\
\hline 6 & 124 & 115 & 143 & $* * * *$ & 8 & 23 & 24 & 21 & 1 & 8 & 35 & 11 & \\
\hline 7 & 148 & 125 & 171 & $* * * *$ & 9 & 31 & 18 & 13 & 62 & 20 & 34 & 18 & 6 \\
\hline 8 & 136 & 124 & 146 & $* * * *$ & 9 & 21 & 30 & 85 & $\begin{array}{ll}5 & 1\end{array}$ & 19 & 16 & 7 & 30 \\
\hline 9 & 128 & 109 & 154 & $* * * *$ & 8 & 9 & 24 & 281 & $15 \quad 1$ & 17 & 24 & 23 & \\
\hline 10 & 125 & 121 & 136 & $* * * *$ & 9 & 25 & 17 & 17 & 42 & 22 & 16 & 10 & 14 \\
\hline 11 & 85 & 71 & 112 & $* * * *$ & 6 & 15 & 26 & 82 & 261 & 10 & & & \\
\hline 12 & 90 & 70 & 114 & $* * * *$ & 5 & 29 & 17 & 172 & 28 & & & & \\
\hline 13 & 110 & 123 & 106 & $* * * *$ & 8 & 13 & 26 & 4 & $\begin{array}{ll}9 & 1\end{array}$ & 15 & 23 & 19 & \\
\hline 14 & 108 & 105 & 113 & $* * * *$ & 8 & 24 & 19 & 21 & 7 & 3 & 16 & 18 & \\
\hline 15 & 116 & 95 & 138 & $* * * *$ & 7 & 15 & 14 & 211 & 16 & 8 & 42 & & \\
\hline 16 & 59 & 48 & 75 & $* * * *$ & 6 & 6 & 12 & 141 & 161 & 12 & & & \\
\hline 17 & 83 & 50 & 126 & $* * * *$ & 5 & 16 & 15 & 143 & 38 & & & & \\
\hline 18 & 66 & 48 & 126 & $* * * *$ & 4 & 35 & 11 & 20 & & & & & \\
\hline$X$ & 50 & 21 & 110 & & 7 & 22 & 24 & 111 & 192 & 21 & $\# 13(21)$ & & \\
\hline Tot: & 2074 & 1840 & 2432 & & 137 & & & & Avera & age & 18 & & \\
\hline
\end{tabular}

SA-cM: sex-averaged cM; M-cM: male-specific cM; F-cM: female-specific cM; p-value: statistical significance of the difference between male- and femalespecific $\mathrm{cM} ;{ }^{* * * *}=<10^{-3} ; \mathrm{N}^{\circ}$ : number of markers per chromosome; Ix: size in $\mathrm{cM}$ of the corresponding marker interval. ${ }^{\#}$ Female and male (between brackets) size of the pseudoautosomal SW980-SW961 interval.

corresponding map was in perfect agreement with previously published marker maps [19]. Four of the unplaced markers were terminal markers which could be placed on either end of the corresponding linkage group (SWR308, SW274, ACR, SW2540), the remaining one being an internal marker for which two adjacent intervals had associated odds of 10:1 (SW1070). The positions of these five markers were fixed according to Rohrer et al. [19] and recombination rates were estimated accordingly. This yielded a marker map flanking a total of 20.74 sex-averaged Morgans (Kosambi), with an average distance of $18 \mathrm{cM}$ between adjacent markers. The number of markers per chromosome averaged 7.2 (range: 4 to 9). Table II summarizes the main features of the used marker map. 


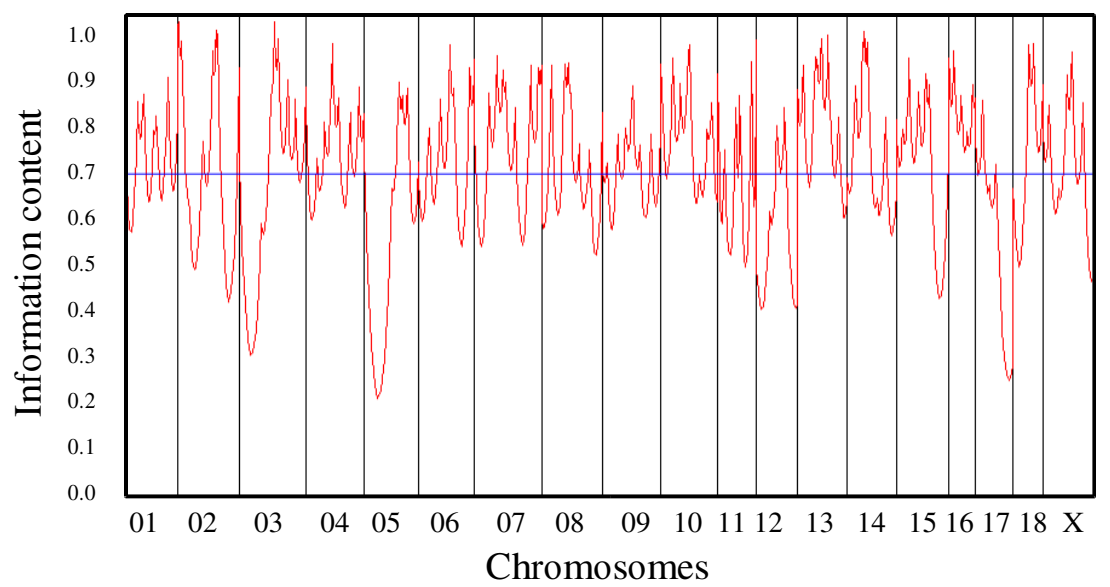

Figure 1. Information content of the used microsatellite marker map. The Y-axis measures the information content computed as described in Section 2. The limits between the different chromosomes are reported by vertical lines, while the corresponding chromosome numbers are given along the $\mathrm{X}$-axis. The vertical line at $68 \%$ corresponds to the average information content across the map.

When computing the likelihood of the pedigree data assuming sex-specific recombination rates, highly significant differences between male and female recombination rates were found for all chromosomes (Tab. II). With the exception of chromosomes 1 and 13 for which the male maps (respectively $142 \mathrm{cM}$ and $123 \mathrm{cM}$ ) proved larger than the female maps (respectively $109 \mathrm{cM}$ and $106 \mathrm{cM}$ ), the female maps of all other chromosomes were systematically larger than the corresponding male maps as expected. The total autosomal map length was estimated at 23.22 Morgans in females versus 18.19 Morgans in males. The genetic length of the $\mathrm{X}$ chromosome was estimated at $110 \mathrm{cM}$ in females, while $21 \mathrm{cM}$ from the pseudoautosomal region (marker interval SW980-SW961) could be traced in male meioses.

Figure 1 illustrates the information content obtained across the genome. It averages $68 \%$, ranging from $24 \%$ to $98 \%$.

\subsection{QTL mapping}

The experiment-wide significance threshold (lod score $>4.6$, accounting for the testing of multiple loci and traits) was exceeded for two chromosomes. A lod score of 20 was reached at the centromeric end of chromosome 2 (map position $1 \mathrm{cM}$ ) for the "\% loin". Significant lod scores (range: 9-18) were obtained at approximately the same position for two other muscularity traits (\% ham, \% lean cuts) as well as three fatness traits (backfat thickness, \% backfat, $\%$ fat cuts). This QTL was shown to be imprinted with an expression of the 
Table III. Characterization of the identified QTL effects.

\begin{tabular}{lcccccc}
\hline Chrom & Position & Trait & Lod score & $2 a$ & $d$ & $\sigma_{\mathrm{R}}$ \\
\hline 7 & $89 \mathrm{cM}$ & Average daily gain $(\mathrm{Kg} /$ day $)$ & 5.6 & 0.09 & $0.01^{\mathrm{NS}}$ & 0.06 \\
7 & $106 \mathrm{cM}$ & Carcass length $(\mathrm{cm})$ & 4.9 & 1.69 & $0.12^{\mathrm{NS}}$ & 1.50 \\
7 & $89 \mathrm{cM}$ & \% belly & 3.3 & 0.90 & $0.14^{\mathrm{NS}}$ & 0.68 \\
1 & $56 \mathrm{cM}$ & BFT (rump) $(\mathrm{mm})$ & 4.1 & 0.43 & $0.18^{* *}$ & 0.32 \\
13 & $10 \mathrm{cM}$ & BFT(average) $(\mathrm{mm})$ & 3.2 & 0.28 & $0.03^{\mathrm{NS}}$ & 0.28 \\
\hline
\end{tabular}

For each significant or suggestive QTL effect, we report: the chromosome, the position on the chromosome (in $\mathrm{cM}$ ), the trait affected (with corresponding units), the corresponding lod score value, the estimated difference between the phenotypic means of alternate homozygotes $2 a=\left|\mu_{\mathrm{PP}}-\mu_{\mathrm{LL}}\right|$, the estimated dominance deviation $d=\left|\mu_{\mathrm{PL} / \mathrm{LP}}-\left(\mu_{\mathrm{LL}}+\mu_{\mathrm{PP}}\right) / 2\right|$, and the residual standard deviation $\sigma_{\mathrm{R}}$. The statistical significance of the corresponding $d$-values is given in superscript: $\mathrm{NS}=$ non significant; ${ }^{* *}=0.01<p<0.05$.

paternal allele only and to map to the $I G F 2$ locus. The corresponding results have been previously reported in detail in Nezer et al. [18], and have been confirmed by others (e.g. [10,3]).

An experiment-wide significant lod score of 5.6 was found on chromosome 7 at map position $79 \mathrm{cM}$ in the interval between markers $S 0066$ and $S W 252$ for average daily gain. A significant effect on carcass length (lod score 4.9; map position $89 \mathrm{cM}$ ) and suggestive effect on \% belly (lod score 3.3; map position $79 \mathrm{cM}$ ) were found in the same region. The corresponding location scores are shown in Figure 2a, while the corresponding maximum likelihood estimates of the genotype means and residual variance are reported in Table III. It can be seen from this table that " $a$ " (i.e. half the difference between alternate homozygotes) ranges from 0.55 to 0.75 residual standard deviations. The dominance deviation " $d$ " ranges from 0.08 to 0.25 residual standard deviations but is never significantly different from zero. Indeed, in none of these cases did $\mathrm{H}_{1}$ prove significantly more likely than $\mathrm{H}_{\mathrm{A}}$. Lod scores superior to 1.4 were found in the same region for \% loin, \% shoulder and lumbar backfat thickness (BFT) indicating that the same QTL likely affects other carcass traits as well (data not shown).

In addition, we found suggestive or nearly suggestive evidence for two additional QTL respectively on chromosomes 1 and 13. A lod score of 4.1 was obtained at map position $56 \mathrm{cM}$ of chromosome 1 , while a lod score of 3.2 was obtained at map position $10 \mathrm{cM}$ of chromosome 13, both for backfat thickness (Fig. 2b,c). The corresponding maximum likelihood estimates of genotype averages and residual standard deviations are reported in Table III. The dominance deviation proved to be significant for the chromosome 1 QTL, but not for the chromosome 13 one. Additional lod scores $>1.4$ were found in 


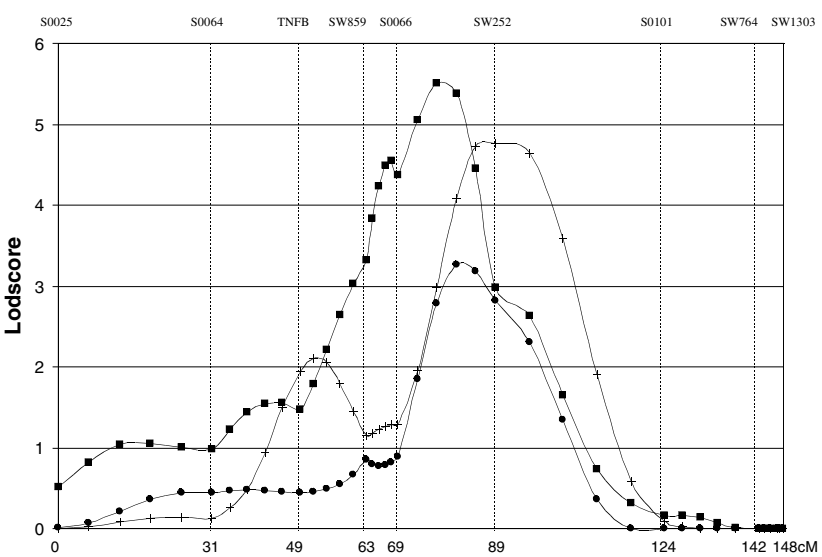

(a)

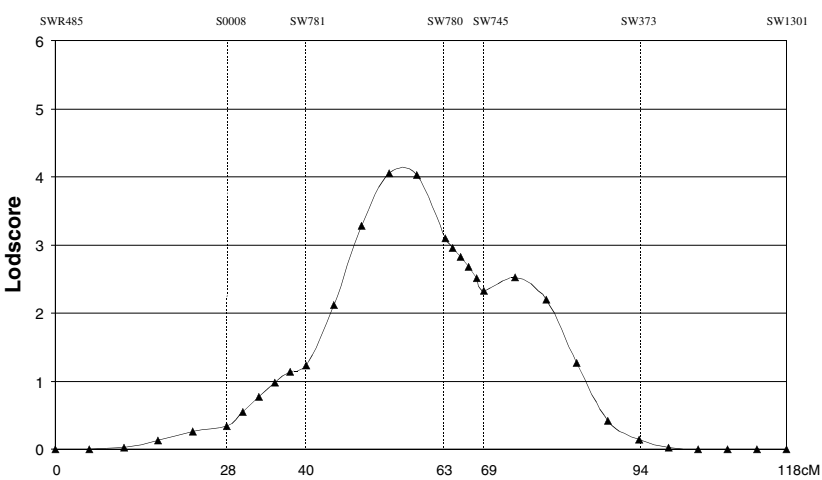

(b)

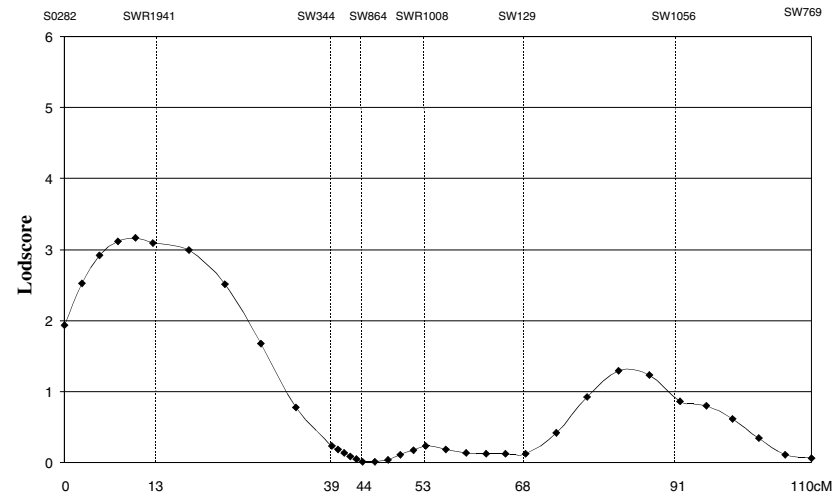

(c)

Figure 2. Lod score profiles obtained on chromosomes SSC7 (a), SSC1 (b) and SSC13 (c) for average daily gain $(\boldsymbol{\square})$, carcass length $(+), \%$ belly $(\bullet)$, rump BFT $(\mathrm{mm})(\boldsymbol{\Delta})$ and average BFT $(\mathrm{mm})(\diamond)$. The names and position (in $\mathrm{cM})$ of the microsatellites used are reported respectively under and above the graph. 
the same chromosome regions for other fat deposition traits (SSC1 and SSC13), as well as for average daily gain (SSC1) (data not shown).

\subsection{Testing for imprinted QTL}

We first tested for evidence that the QTL identified on chromosomes 1, 7 and 13 might be imprinted using the procedure described in Section 2. For these three chromosomes, the likelihood of the data were systematically higher under the hypothesis of a Mendelian QTL than under that of imprinted QTL whether paternally or maternally imprinted, indicating that neither of these QTL is likely to be imprinted.

We then performed a whole genome scan comparing the likelihood of the data under the $\mathrm{H}_{\mathrm{IM}}$ and $\mathrm{H}_{\mathrm{IP}}$ hypotheses versus the $\mathrm{H}_{0}$ hypotheses. We did not obtain lod scores that would reach the significant (4) or suggestive (2.8) thresholds for any of the chromosomes. Our data therefore did not provide evidence for the existence of imprinted QTL other than the one on chromosome 2 [18].

\section{DISCUSSION}

We herein report the results of a whole genome scan performed in a Piétrain $\times$ Large White intercross to map QTL influencing growth and carcass traits. The identification of an imprinted QTL with major effect on muscle mass and fat deposition on chromosome 2 in this same material has been previously reported [18]. In this paper, we describe the identification of a QTL influencing average daily gain, carcass length and to a lesser extent fat deposition on pig chromosome 7. QTL affecting carcass traits have been previously reported on pig chromosome 7 by several authors. Most of these studies were based on intercross populations generated from Chinese $\times$ European F1 parents (e.g. [2, $3,20,21,23])$. The most likely position of the QTL identified in these studies systematically coincided with the TNF $\beta$ and MHC loci around position $50 \mathrm{cM}$ on our map (Fig. 2a). This was approximately $35 \mathrm{cM}$ away from the most likely position of the QTL found in this study and outside of the lod -2 drop off interval, suggesting that we uncovered a different QTL in this study. Note that in a recent study performed by Malek et al. [16] in a Berkshire $\times$ Yorkshire intercross, a QTL with experiment-wide significance on backfat was reported with a maximum likelihood position in between the two former QTL.

In addition, we report two suggestive QTL affecting backfat thickness, respectively on chromosomes 1 and 13. QTL with major effect on growth and carcass traits have been reported at the telomeric end of pig chromosome 1 
by Rohrer et al. [20,21], de Koning et al. [3] and Bidanel et al. [2]. All these studies were performed in F2 crosses involving Chinese and European parental lines. Based on its maximum likelihood position, it seems unlikely that the QTL reported in this work would be the same. However, Malek et al. [16], have reported QTL influencing backfat thickness close to the QTL reported in this work. Moreover, closer examination of the location scores reported by de Koning et al. [3] are suggestive of a QTL that could coincide with ours in addition to the telomeric one. These results support the real nature of the suggestive QTL found in this study on chromosome 1. Suggestive evidence for a QTL influencing backfat thickness on the centromeric half of chromosome 13 were reported by Rohrer et al. [20,21], Malek et al. [16] and Bidanel et al. [2], again in support of the real nature of the suggestive effect uncovered in this analysis.

We did not find evidence for imprinted QTL on chromosomes other than 2 in this experiment. Therefore, this contradicts the recent report by de Koning et al. [4] claiming the existence of multiple imprinted QTL for carcass and growth traits in the pig genome. The reason for this discrepancy remains unclear. It could reflect the limited detection power of our experimental design due to the limited number of analysed F2 individuals $(<530)$, the missing phase information in the F1 generation, and the very stringent significance thresholds used.

As a result of the missing phase information in the $\mathrm{F} 1$ generation, we cannot formally determine the parental origin of the QTL alleles responsible for the effects detected on chromosomes 1, 7 and 13. We assumed a priori that the QTL alleles increasing average daily gain, carcass length, and fat deposition originate from the Large White population. Genotyping additional relatives with chromosome 2 markers allowed us to trace the parental origin of the chromosome 2 QTL alleles, demonstrating that as expected the allele increasing muscle mass while decreasing fat deposition originated from the Piétrain founder animals [18].

\section{ACKNOWLEDGEMENTS}

This work was supported by the Belgian ministère des Classes Moyennes et de l'Agriculture. We are very grateful to Professor Hanset for initiating this experiment and for Professor Leroy for his support and interest in this work. We acknowledge V. Verleyen, S. Scalais, L. Grobet, C. Schirvel and C. Dasnois for their help in collecting and organizing the biological samples and phenotypic data. Sincere thanks to M. Rothschild for providing us with numerous primer pairs for microsatellite amplification, and to Seghers Hybrid for their support and interest in this work. 


\section{REFERENCES}

[1] Andersson L., Genetic dissection of phenotypic diversity in farm animals, Nat. Rev. Genet. 2 (2001)130-138.

[2] Bidanel J.P., Milan D., Iannuccelli N., Amigues Y., Boscher M.Y., Bourgeois F., Caritez J.C., Gruand J., Le Roy P., Lagant H., Quintanilla R., Renard C., Gellin J., Ollivier L., Chevalet C., Growth and fatness genes in pigs, Genet. Sel. Evol. 33 (2001) 289-309.

[3] de Koning D.J., Janss L.L.G., Rattink A.P., van Oers P.A.M., de Vries B.J., Groenen M.A.M., van der Poel J.J., de Groot P.N., Brascamp E.W., van Arendonk J.A.M., Detection of quantitative trait loci for backfat thickness and intramuscular fat content in pigs (Sus scrofa), Genetics 152 (1999) 1679-1690.

[4] de Koning D.J., Rattink A.P., Harlizius B., van Arendonk J.A., Brascamp E.W., Groenen M.A., Genome-wide scan for body composition in pigs reveals important role of imprinting, Proc. Nat. Acad. Sci. (USA) 97 (2000) 7947-7950.

[5] Falconer D.S., Mackay T.F.C., Introduction to Quantitative Genetics, 4th Ed., Longman Scientific and Technical, New York, 1996.

[6] Flint J., Mott R., Finding the molecular basis of quantitative traits: successes and pitfalls, Nat. Rev. Genet. 2 (2001) 437-445.

[7] Fuji J., Otsu K., Zorzato F., Deleon S., Khanna V.K., Weiler J.E., O’Brien P.J., MacLennan D.H., Identification of a mutation in the porcine ryanodine receptor associated with malignant hyperthermia, Science 253 (1991) 448-451.

[8] Georges M., Nielsen D., Mackinnon M., Mishra A., Okimoto R., Pasquino A.T., Sargeant L.S., Sorensen A., Steele M.R., Zhao X., Womack J.E., Hoeschele I., Mapping quantitative trait loci controlling milk production by exploiting progeny testing, Genetics 139 (1995) 907-920.

[9] Hanset R., Dasnois C., Scalais S., Michaux C., Grobet L., Effets de l'introgression dans le génome Piétrain de l'allèle normal au locus de sensibilité à l'halothane, Genet. Sel. Evol. 27 (1995) 77-88.

[10] Jeon J.T., Carlborg Ö., Törnsten A., Giuffra E., Amarger V., Chardon P., Andersson-Eklund L., Andersson K., Hansson I., Lundström K., Andersson L., A paternally expressed QTL affecting skeletal and cardiac muscle mass in pigs maps to the IGF2 locus, Nat. Genet. 21 (1999) 157-158.

[11] Knott S.A., Marklund L., Haley C.S., Andersson K., Davies W., Ellegren H., Fredholm M., Hansson I., Hoyheim B., Lundström K., Moller M., Andersson L., Multiple marker mapping of quantitative trait loci in a cross between outbred wild boar and large white pigs, Genetics 149 (1998) 1069-1080.

[12] Kruglyak L., Lander E.S., A nonparametric approach for mapping quantitative trait loci, Genetics 139 (1995) 1421-1428.

[13] Kruglyak L., Lander E.S., Genetic dissection of complex traits: guidelines for interpreting and reporting linkage results, Nat. Genet. 11 (1995) 241-247.

[14] Lalouel J.M., Optimization of functions, Contrib. Epidemiol. Biostat. 4 (1983) 235-259.

[15] Lander E., Green P., Construction of multilocus genetic linkage maps in humans, Proc. Nat. Acad. Sci. (USA) 84 (1987) 2363-2367.

[16] Malek M., Dekkers J.C.M., Lee H.K., Baas T.J., Rotschild M.F., A molecular genome scan analysis to identify chromosomal regions influencing economic 
traits in the pig. I. Growth and body composition, Mamm. Genome 12 (2001) 630-636.

[17] MacLennan D.H., Phillips M.S., Malignant hyperthermia, Science 256 (1993) 789-794.

[18] Nezer C., Moreau L., Brouwers B., Coppieters W., Detilleux J., Hanset R., Karim L., Kvasz A., Leroy P., Georges M., An imprinted QTL with major effect on muscle mass and fat deposition maps to the IGF2 locus in pigs, Nat. Genet. 21 (1999) 155-156.

[19] Rohrer G.A., Alexander L.J., Hu Z., Smith T.P., Keele J.W., Beattie C.W., A comprehensive map of the porcine genome, Genome Res. 6 (1996) 371-391.

[20] Rohrer G.A., Keele J.W., Identification of quantitative trait loci affecting carcass composition in swine: II. Muscling and wholesale product yield traits, J. Anim. Sci. 76 (1998) 2255-2262.

[21] Rohrer G.A., Keele J.W., Identification of quantitative trait loci affecting carcass composition in swine: I. Fat deposition traits, J. Anim. Sci. 76 (1998) 2247-2254.

[22] Spelman R.L., Coppieters W., Karim L., van Arendonk J.A.M., Bovenhuis H., Quantitative trait loci analysis for five milk production traits on chromosome six in the dutch Holstein-Friesian population, Genetics 144 (1996) 1799-1808.

[23] Wang L., Yu T.P., Tuggle C.K., Liu H.C., Rothschild M.F., A directed search for quantitative trait loci on chromosomes 4 and 7 in pigs, J. Anim. Sci. 76 (1998) 2560-2567.

To access this journal online: www.edpsciences.org 